Author's Final Submitted Version: The orginal article was published in "Current Protein \& Peptide Science" and is available at the Bentham Science website http://www.eurekaselect.com/122090/article.

\title{
Vaccination approaches against opportunistic fungal infections caused by Aspergillus fumigatus
}

Utz Reichard ${ }^{1, *}$, Sahra Herrmann ${ }^{1}$ and Abdul R. Asif ${ }^{2}$

${ }^{1}$ Department of Medical Microbiology and German National Reference Center for Systemic Mycoses, University Medical Center, Goettingen, ${ }^{2}$ Department of Clinical Chemistry, University Medical Center, Goettingen, Germany

\section{KEYWORDS}

fungus, vaccine, protective antigens, immunity, Aspergillus fumigatus

*Address correspondence to this author: Department of Medical Microbiology, University Medical Center of Goettingen, Kreuzbergring 57, 37075 Goettingen, Germany, Tel: +49-(0)551-395856; Fax: +49-(0)551-395860; E-mail: ureicha@gwdg.de 


\section{ABSTRACT}

Although innate immunity primarily combats systemic infections of opportunistic fungi such as Aspergillus and Candida spp., acquired and protective immunoreactions were observed long ago in animal trials following sublethal systemic infections caused by viable fungi or after challenging animals with inactivated fungal cells. Based on these observations, fungal antigens should exist which mediate such protective immunoreactions and have in part already been identified. In this context, this review focuses primarily on the various approaches that have been used to identify protection-mediating Aspergillus-antigens and their rationale. Emphasis is placed on screening methods that have exploited genetic or proteomic approaches on the basis of the corresponding fungal genome projects. Thereby, a survey and description is given of the antigens so far known to be capable of inducing immune responses that protect animals against acquiring lethal systemic aspergillosis. 


\section{INTRODUCTION}

Aspergillus fumigatus is the most important mold, causing invasive opportunistic infections in the immunocompromised host (for reviews see [1-4]). Patients suffering from leukemia or undergoing hematopoietic stem cell transplantation (HSCT) are predominantly prone to pulmonary and systemic aspergillosis, respectively. Recently, a large prospective surveillance study on the basis of 16,200 HSCTs revealed 12-month cumulative incidence rates of 1.2 to $8.1 \%$ for invasive fungal infections (IFIs), with $43 \%$ of these being aspergillosis, by far the most prevalent agent [5]. Therefore, the main risk factors for acquiring the disease are neutropenia and cortisone administration. Consequently, invasive aspergillosis occurs as an early infection during neutropenia in the course of the induction cycle of chemotherapy and as a late form when the bone marrow has recovered but cortisone treatment is necessary, particularly if the picture is complicated by graft-versus-host disease (GVDH). In those patients receiving allogeneic transplants, mortality rates of invasive aspergillosis still reach up to 60 to $70 \%$ in spite of significant improvements in antifungal therapeutic options during the last decade [6-8]. In addition, invasive aspergillosis is a serious problem in other underlying diseases that are accompanied by immunosuppression, for example in patients with solid organ transplantations. The overall 12-week mortality of invasive aspergillosis in these patients is about $30 \%$ [9]. On the other hand, considering all underlying diseases leading to invasive aspergillosis, 12-week overall mortality rates between 35 and $45 \%$ are currently reported, despite antifungal therapy [10-11].

Altogether, invasive aspergillosis remains a life-threatening disease for the immunocompromised host despite substantial progress in antifungal therapy. Therefore, alternative prophylactic or therapeutic options would be of high value and a vaccination approach would be one of them. At any rate, in this context, two major 
questions have to be answered. The first is whether a vaccine that would have the ability to induce a protective immune response in a host with a functional immune system may also be applicable in the immunocompromised patient. This question is connected with the vaccination procedure itself and the search for proper adjuvants to elicit the desired type of immune response. The second question is whether any antigens at all exist that may induce a protective response, and how to identify those antigens.

This review will focus on the second question and thereby, in particular, on the various experimental approaches that have been used to identify protectionmediating Aspergillus-antigens and their rationale. In this respect, this review complements other reviews on fungal vaccine development and their experimental findings and approaches that have already been published [12-21]. In addition, a list and description of antigens that have so far been successfully proven to induce a protective immune response against systemic Aspergillus infection in animals will be provided. 


\section{RATIONALE FOR THE SEARCH FOR PROTECTIVE ANTIGENS}

The chances of developing a successful vaccine are dependent on the identification of protection-mediating antigens. In general, chances are good when natural infection with the microorganism induces a permanent and sustainable acquired immunity (for review e.g. see [22]). This basically means that, during infection, the microorganism expresses antigens in substantial amounts that are capable of mediating a protective response. Consequently, if these antigens, for example, are produced in vitro (e.g. recombinantly) or in vivo (e.g., by an attenuated living microorganism), they could form the basis for a vaccine. In contrast, chances are poor if no permanent immunity is produced by the natural infection. Well known examples of both cases exist: there are childhood diseases that characteristically induce permanent acquired immunity against which vaccines have been successfully developed (e.g., measles, chickenpox, rubella). On the other hand, the search for a vaccine against HIV or malaria turned out to be extremely challenging and difficult. Neither disease elicits a protective acquired immune response or, at least in the case of malaria, does not induce a microbiological but rather a clinical immunity that develops very slowly and is not very sustainable (for reviews see, e.g., [23]and [24]).

As A. fumigatus primarily accounts for opportunistic infections, there are almost no "natural" systemic infections in immunocompetent humans; thus, we simply cannot know whether Aspergillus releases antigens capable of mediating a protective response. However, we do possess several direct and indirect indications. First, dimorphic but related fungi with greater virulence than $A$. fumigatus, for example Histoplasma capsulatum and Coccidioides immitis, cause a protective CD4+ TH1 cellular immune response after infection of the lung that typically evolves within weeks after infection (for review see [25-26]). Second, and most important, the

development of a protective immune response that is able to prevent systemic 
Aspergillus infections has been shown in animals and will be depicted in the following sections.

\section{Basic observations and experiments}

In 1976, Lehmann and White showed in mice that after a localized kidney infection with $A$. fumigatus brought about by i.v. administration had been present for some time, these animals acquired a systemic immunity against another i.v. infection that was not affected by cortisone [27]. At the same time, Corbel and Eades found that adult mice showed considerably greater resistance to Aspergillus infection than young animals of the same strain [28]. Both observations led to several vaccine studies and closer immunological investigations. First, a vaccine study in turkey poults was conducted with preparations from different growth stages of the fungus [29]. Interestingly, an inactivated germ-line vaccine, administered s.c., showed the highest protection rate of $38 \%$ against an otherwise deadly aerosol challenge with Aspergillus spores [29]. In 1993, it was found that immunity induced by a sublethal i.v. infection in mice was not transferable by serum but by macrophages from a splenocyte cell fraction of an immune animal to a naïve one [30]. The role of the cellular immunoreaction was further underlined when, after nasal vaccination with either viable $A$. fumigatus conidia or a preparation from crude culture filtrate, protection was induced and then experimentally transferred with Ag-specific CD4 ${ }^{+} \mathrm{T}$ cells from the immune animal to naïve recipients [31].

Ito et al. also found that a crude filtrate of a 14-day old Aspergillus culture did confer some protection in mice when administered s.c. or intranasally. However, the effects were not significant. In contrast, in the same experimental setting, a sonicated 7-day old hyphal mass conferred significant protection, as well as mice infected intranasally with a sublethal challenge of viable conidia [32]. 


\section{SCREENING APPROACHES FOR PROTECTIVE ANTIGENS}

For infections caused by $A$. fumigatus, an acquired protective immune response can be induced in animals. As described above, historically the protective response was observed after a nonlethal infection with the pathogen or after vaccination with whole, inactivated fungal cells, cellular sub-fractions or culture supernatants. However, for humans and particularly for immunosuppressed individuals, neither a vaccine approach based on living organisms nor on undefined crude fractions or extracts is an option. Thus, a search for very specific fungal antigens that mediate the protective response was emphasized. In this section, systematic screening approaches and their findings are summarized.

A systematic approach to identify possible vaccine candidates of $A$. fumigatus was performed by Denikus et al. [33]. Ten rabbits were infected i.v. with A. fumigatus conidia in sublethal doses and some of them developed an acquired protective immune response against further systemic infections. Blood from the rabbits was collected prior to the first infection and during the course of it. Subsequently, a cDNAexpression-library based on young germinating conidia (germlings) was screened with the convalescent sera of the animals. The rationale behind this screening approach was that the protective immune response, even if primarily based on a Tcell reaction, should elicit also a humeral response, as at least most large proteins should contain both T-cell and B-cell epitopes. Altogether, the 36 proteins identified by this method should, at minimum, primarily reflect those that are immunodominant and / or expressed abundantly in the protection-inducing infection model. Among these proteins were the allergens Asp f 16 (or Asp f 9 - see below) and Aspf 3 (also called AHP1) for which protection-inducing properties against invasive aspergillosis were shown shortly before or after this study [34-35]. However, as cDNA-library 
screening with convalescent rabbit sera may not reveal all reacting antigens, the same group later used the sera for a 2D-Western blot screening based on protein extracts of $A$. fumigatus germlings [36]. Reacting spots were analyzed by mass spectrometry and a list of 59 different proteins was generated. The proteins were again listed, including a rough estimate of their reaction intensities. Among these proteins were, once again, the allergen Asp $f 3$ but, in addition, 1,3glucanosyltransferase (Gel1) was present. Recombinant Gel1 was used as a vaccine in mice a short while ago and was also proven to mediate a protective acquired immune reaction [18] (see below).

Ito et al. also conducted a systematic screening approach on the basis of animals that had developed an acquired immunity against invasive aspergillosis [35]. To this end, mice were either s.c. immunized with crude culture filtrate (CF) of the fungus or subjected to a sublethal intranasal infection with viable conidia (VC). In particular, sera from mice that survived the latter challenge reacted with a $19.5 \mathrm{kDa}$ band in Western blots based on hyphal protein extracts. In mass spectrometric analysis, this band could also be attributed to Asp $f 3$ (AFUA_6G02280). Recombinant Asp f 3 or truncated versions lacking lgE-binding sites were shown to be protective in animal vaccination trials [35].

Based on the assumption that the immune system first comes into contact with superficial antigens, particularly of $A$. fumigatus conidia, conidial surface proteins were extracted by Asif et al. [37]. The corresponding proteome was then analyzed by 2D-gelelectrophoresis and mass-spectrometry based on data of the A. fumigatus genome project [38]. Altogether 26 different proteins were identified, twelve of which contained a signal for secretion. Among these was the acid protease PEP2, for which protective properties were shown later in animal vaccination trials [18]. Once again, the allergen Asp f 3 was identified among the proteins without a secretion signal [37]. 
To gain insights into early germination events and facilitate the identification of potential stage-specific biomarkers and vaccine candidates, Suh et al. had used quantitative shotgun proteomics to elucidate patterns of protein abundance changes during early fungal development [39]. Cell wall extracts of either dormant conidia, isotropically expanding conidia, conidia with small germ tubes or with longer, preseptated hyphae were analyzed by LC-MS/MS using LTQ ion trap mass spectrometry. Protein abundance was monitored using APEX (absolute protein expression). A battery of 375 different proteins was thereby identified of which 59 were specifically enriched in dormant conidia. Remarkably, the conidial proteome was dominated by small lineage-specific proteins of unknown function. Among the proteins listed were all those so far positively tested to induce protection in mice (Asp f 9/16, Asp f 3, Gel1, Pep2). While Asp f 9/16 was only detected in pre-septated hyphae, Aspf 3, Gel1 and Pep2 were detected in all growth phases as well as in dormant conidia. Aspf 3 was particularly abundant. 


\section{DIRECT TESTING APPROACHES}

In 2002 Bozza et al. published the first vaccination study in mice in which a defined antigen of $A$. fumigatus administered together with a CpG-adjuvant promoting a dominant Th1-response was shown to elicit a protective acquired immune response to invasive aspergillosis [34]. The antigen was Asp f 16, which, as deduced from its amino acid sequence, is most likely identical with Asp f 9, both of which had been described as possessing extensive sequence homology and characterized previously as $A$. fumigatus allergens in patients suffering from allergic bronchopulmonary aspergillosis (ABPA) [40-41] (Table 1). Blast searches based on the data of the $A$. fumigatus genome project (Af293 strain) do not support the existence of two closely related genes encoding slightly different proteins but rather of one (our own investigations) [38].

In 2009 , the same group assessed a variety of $A$. fumigatus recombinant proteins for their ability to induce protection in naïve and bone marrow transplanted mice in a dendritic cell (DC) model of vaccination [18]. At least three proteins were shown to induce such a response, namely, a protease (Pep1) [42] and two glycosylphosphatidylinositol (GPI)-anchored proteins, Gel1 (a 1,3-_ glucanosyltransferase; Afu 2g01170) and Crf1 (or Asp f 9; a cell wall glucanase; Afu 1g16190) [43]. However, as mentioned above, Crf1 or Asp f 9 is most likely identical with Asp f 16, which had already been described as being protective by the same group. In addition, although, Pep1 was referred to as a secreted protease from $A$. fumigatus in the discussion in the article [18], the corresponding citation and accession-No. (Afu $3 g 11400$ ) refer to Pep2, which in fact is a cellular and primarily vacuolar protease of the fungus [42]. It is the very same enzyme that was detected before on the $A$. fumigatus conidial surface, probably as a kind of moonshine protein (see Table 1 and [37]). 


\section{LIST OF PROTECTIVE PROTEIN ANTIGENS IDENTIFIED}

To the best of our knowledge, four individual proteins so far have been proven to induce a protective immune response to systemic aspergillosis in animal trials. The antigens and their characteristics are given in Table 1.

Table 1

\begin{tabular}{|l|l|l|l|l|l|l|}
\hline antigen & synonyms & Acc. No. & function & $\begin{array}{l}\text { localization, } \\
\text { remarks }\end{array}$ & $\begin{array}{l}\text { reference } \\
\text { in which } \\
\text { protection } \\
\text { was first } \\
\text { shown }\end{array}$ & $\begin{array}{l}\text { other } \\
\text { selected } \\
\text { references } \\
\text { with } \\
\text { respect to } \\
\text { vaccination }\end{array}$ \\
\hline $\begin{array}{l}\text { Asp f } \\
16\end{array}$ & $\begin{array}{l}\text { likely } \\
\text { identical } \\
\text { with Asp f } \\
9 \text { or Crf 1 }\end{array}$ & AFUA_1g16190 & glucanase & $\begin{array}{l}\text { cell wall, } \\
\text { GPI- } \\
\text { anchored }\end{array}$ & {$[34]$,} & {$[18,33,39]$} \\
\hline Asp f 3 & $\begin{array}{l}\text { Pmp20, } \\
\text { Ahp1 }\end{array}$ & AFUA_6G02280 & peroxireductase & $\begin{array}{l}\text { peroxisomal, } \\
\text { cell wall (no } \\
\text { signal), } \\
\text { abundantly } \\
\text { expressed }\end{array}$ & {$[35]$} & $\begin{array}{l}{[33,36-37,} \\
\text { cell wall, } \\
\text { GPI- } \\
\text { anchored }\end{array}$ \\
\hline Gel 1 & - & AFUA_2g01170 & $\begin{array}{l}1,3- \\
\text { glucanosyltransferase }\end{array}$ & [18] & {$[18,36,39]$} \\
\hline Pep2 & - & AFUA_3g11400 & $\begin{array}{l}\text { aspartic } \\
\text { endoprotease }\end{array}$ & $\begin{array}{l}\text { vacuole, cell } \\
\text { wall }\end{array}$ & {$[18]$} & {$[18,37,39$,} \\
\hline
\end{tabular}




\section{CONCLUSION AND FUTURE PERSPECTIVES}

A protective immune response could be induced in animals after either a nonlethal systemic infection with A. fumigatus or after vaccination with crude fungal elements or culture supernatant [27-32]. Based on the assumption that, as in animals, a protective immune response against invasive aspergillosis may also be induced in humans, a search for single fungal antigens that could elicit such a response started approximately a decade ago.

So far, four different protein antigens have tested positive, consisting of Asp $f$ 16 (likely identical with Asp f 9, also called Crf1) [34], Asp f 3 (also called Ahp1) [35], Gel 1 and Pep2 [18]. Asp f 16 and Gel1 are GPI-anchored and attached to the fungal cell wall (for characteristics and review see [43]). As a glucanase belonging to the Crh/Crf-family, Asp f 16 is involved in the crosslinking of chitin to $\beta(1,6)$-glucan; Gel1, (Gas/Gel-family) as a 1,3-glucanosyltransferase, elongates $\beta(1,3)$-glucans. Both are presumably involved in remodeling processes at plastic cell wall tips. Thus, the antigens are not only on the cell surface and easily accessible to the immune system for uptake and recognition but also should be more or less constitutively expressed when the fungus is growing. In addition, they fulfill important functions in the growth process and, if recognized by the humeral immune system, these functions may be blocked. Therefore, although we know experimentally that acquired immunity to fungi is primarily mediated by $\mathrm{Th} 1 \mathrm{CD}^{+}$and $\mathrm{CD} 8^{+} \mathrm{T}$-cell responses [12, 46-51], this humeral response may also contribute to protective immunity, or at least partly compensate the otherwise antagonistic effects of a Th2-response with respect to the essential cellular Th1-response.

The other two antigens so far known to elicit protection in mice are Asp f 3 and Pep2. Asp f 3 (also known as Ahp1) is a peroxireductase with no secretion signal. However, it is also found on the cell wall surface of conidia and is abundantly present 
in association with the cell wall in all young growing stages of the fungus [37, 39]. Therefore, from its function as well as from its localization, it is likely that the enzyme is involved in protecting the fungus against oxidative stress by inactivating corresponding radicals. As oxidative stress in general is thought to be one of the major defense mechanisms used by the host's neutrophils and macrophages to combat fungal invasion [52-55], once again, recognition may not be the sole reason immunity develops. In line with this, it was shown that removing either or both of the IgE-binding sites to avoid allergic and abundant humeral responses conferred even better protection, at least when a single epitope was left in the truncated form [35]. Last but not least, Pep2 conferred a protective immune response when used as a recombinant vaccine in mice [18]. This enzyme is an aspartic endoprotease with a presumably primarily vacuolar location, but is also found attached to the fungal cell wall, particularly in Aspergillus conidia [37, 39, 42]. The conidial wall localization is somewhat surprising, but in fact may provide the fungal cell access to degradation of host proteins during the first step of infection. Thus it is conceivable that a vaccine based on Pep2 may not only work because the protein serves as a recognition anchor. Inhibitory effects mediated by the immune response may also play a role.

All recombinant antigens that were able to induce protective immune reactions against invasive aspergillosis in mice have been listed as possible vaccine candidates in respective screening protocols [33, 35-37, 39]. These protocols were based on the observation that either a nonlethal fungal infection or vaccination with whole, inactivated fungal cells, cellular subfractions or culture supernatants conferred immunity. Of particular interest are (i) antigens identified from the early immunoreaction of animals that developed immunity after a systemic infection and (ii) molecules on the cell surface of conidia and young fungal growing stages (germlings), as these are early antigens and readily accessible to the immune system 
when the infection starts. In addition to the exploitation of antigens already successfully identified in animal vaccine trials, further research on suitable candidates should follow. Since a broad list of possible vaccine candidates exists, a systematic approach to test them is required in future. 


\section{ACKNOWLEDGEMENTS}

We are indebted to Iris Iben and Helmut Eiffert for careful reading and correcting of the manuscript. 


\section{REFERENCES}

[1] Dagenais, T. R.; Keller, N. P. Pathogenesis of Aspergillus fumigatus in Invasive Aspergillosis. Clin Microbiol Rev, 2009, 22(3), 447-465.

[2] Latge, J. P. Aspergillus fumigatus and aspergillosis. Clin Microbiol Rev, 1999, 12(2), 310-350.

[3] Brakhage, A. A. Systemic fungal infections caused by Aspergillus species: epidemiology, infection process and virulence determinants. Curr Drug Targets, 2005, 6(8), 875-886.

[4] Patterson, T. F. In: Mandell, Douglas, and Bennett's principles and practice of infectious diseases; Mandell, G. L.; Bennett, J. E.; Dolin, R., Eds.; Churchill Livingstone/Elsevier: Philadelphia, PA, 2010; pp 3241-3255.

[5] Kontoyiannis, D. P.; Marr, K. A.; Park, B. J.; Alexander, B. D.; Anaissie, E. J.; Walsh, T. J.; Ito, J.; Andes, D. R.; Baddley, J. W.; Brown, J. M.; Brumble, L. M.; Freifeld, A. G.; Hadley, S.; Herwaldt, L. A.; Kauffman, C. A.; Knapp, K.; Lyon, G. M.; Morrison, V. A.; Papanicolaou, G.; Patterson, T. F.; Perl, T. M.; Schuster, M. G.; Walker, R.; Wannemuehler, K. A.; Wingard, J. R.; Chiller, T. M.; Pappas, P. G. Prospective surveillance for invasive fungal infections in hematopoietic stem cell transplant recipients, 2001-2006: overview of the Transplant-Associated Infection Surveillance Network (TRANSNET) Database. Clin Infect Dis, 2010, 50(8), 1091-1100.

[6] Mihu, C. N.; King, E.; Yossepovitch, O.; Taur, Y.; Jakubowski, A.; Pamer, E.; Papanicolaou, G. A. Risk factors and attributable mortality of late aspergillosis after T-cell depleted hematopoietic stem cell transplantation. Transpl Infect Dis, 2008, 10(3), 162-167. 
[7] Mikulska, M.; Raiola, A. M.; Bruno, B.; Furfaro, E.; Van Lint, M. T.; Bregante, S.; Ibatici, A.; Del Bono, V.; Bacigalupo, A.; Viscoli, C. Risk factors for invasive aspergillosis and related mortality in recipients of allogeneic SCT from alternative donors: an analysis of 306 patients. Bone Marrow Transplant, 2009, 44(6), 361-370.

[8] Li, L.; Wang, J.; Zhang, W.; Yang, J.; Chen, L.; Lv, S. Risk factors for invasive mold infections following allogeneic hematopoietic stem cell transplantation: a single center study of 190 recipients. Scand J Infect Dis, 2012, 44(2), 100-107.

[9] Neofytos, D.; Fishman, J. A.; Horn, D.; Anaissie, E.; Chang, C. H.; Olyaei, A.; Pfaller, M.; Steinbach, W. J.; Webster, K. M.; Marr, K. A. Epidemiology and outcome of invasive fungal infections in solid organ transplant recipients. Transpl Infect Dis, 2010, 12(3), 220-229.

[10] Steinbach, W. J.; Marr, K. A.; Anaissie, E. J.; Azie, N.; Quan, S. P.; MeierKriesche, H. U.; Apewokin, S.; Horn, D. L. Clinical epidemiology of 960 patients with invasive aspergillosis from the PATH Alliance registry. J Infect, 2012.

[11] Lortholary, O.; Gangneux, J. P.; Sitbon, K.; Lebeau, B.; de Monbrison, F.; Le Strat, Y.; Coignard, B.; Dromer, F.; Bretagne, S. Epidemiological trends in invasive aspergillosis in France: the SAIF network (2005-2007). Clin Microbiol Infect, 2011, 17(12), 1882-1889.

[12] Ito, J. I. T cell immunity and vaccines against invasive fungal diseases. Immunol Invest, 2011, 40(7-8), 825-838.

[13] Stevens, D. A. Vaccinate against aspergillosis! A call to arms of the immune system. Clin Infect Dis, 2004, 38(8), 1131-1136.

[14] Deepe, G. S., Jr. Preventative and therapeutic vaccines for fungal infections: from concept to implementation. Expert Rev Vaccines, 2004, 3(6), 701-709. 
[15] Dixon, D. M.; Casadevall, A.; Klein, B.; Mendoza, L.; Travassos, L.; Deepe, G. S., Jr. Development of vaccines and their use in the prevention of fungal infections. Med Mycol, 1998, 36 Suppl 1, 57-67.

[16] Feldmesser, M. Prospects of vaccines for invasive aspergillosis. Med Mycol, 2005, 43(7), 571-587.

[17] Segal, E. Vaccines against fungal infections. Crit Rev Microbiol, 1987, 14(3), 229-271.

[18] Bozza, S.; Clavaud, C.; Giovannini, G.; Fontaine, T.; Beauvais, A.; Sarfati, J.; D'Angelo, C.; Perruccio, K.; Bonifazi, P.; Zagarella, S.; Moretti, S.; Bistoni, F.; Latge, J. P.; Romani, L. Immune sensing of Aspergillus fumigatus proteins, glycolipids, and polysaccharides and the impact on Th immunity and vaccination. J Immunol, 2009, 183(4), 2407-2414.

[19] Ito, J. I.; Lyons, J. M.; Diaz-Arevalo, D.; Hong, T. B.; Kalkum, M. Vaccine progress. Med Mycol, 2009, 47 Suppl 1, S394-400.

[20] Casadevall, A.; Feldmesser, M.; Pirofski, L. A. Induced humoral immunity and vaccination against major human fungal pathogens. Curr Opin Microbiol, 2002, 5(4), 386-391.

[21] Casadevall, A. Antibody immunity and invasive fungal infections. Infect Immun, 1995, 63(11), 4211-4218.

[22] Plotkin, S. A. History of vaccine development, Springer: New York, 2011.

[23] Koff, W. C. HIV vaccine development: challenges and opportunities towards solving the HIV vaccine-neutralizing antibody problem. Vaccine, 2012, 30(29), $4310-4315$.

[24] Miller, L. H.; Good, M. F. The main obstacle to a malaria vaccine: the malaria parasite. Vaccine, 1988, 6(2), 104-106. 
[25] Deepe, G. S., Jr. In: Mandell, Douglas, and Bennett's principles and practice of infectious diseases; Mandell, G. L.; Bennett, J. E.; Dolin, R., Eds.; Churchill Livingstone/Elsevier: Philadelphia, PA, 2010; pp 3305-3318.

[26] Galgiani, J. N. In: Mandell, Douglas, and Bennett's principles and practice of infectious diseases; Mandell, G. L.; Bennett, J. E.; Dolin, R., Eds.; Churchill Livingstone/Elsevier: Philadelphia, PA, 2010; pp 3333-3344.

[27] Lehmann, P. F.; White, L. O. Acquired immunity to Aspergillus fumigatus. Infect Immun, 1976, 13(4), 1296-1298.

[28] Corbel, M. J.; Eades, S. M. Examination of the effect of age and acquired immunity on the susceptibility of mice to infection with Aspergillus fumigatus. Mycopathologia, 1977, 60(2), 79-85.

[29] Richard, J. L.; Thurston, J. R.; Cutlip, R. C.; Pier, A. C. Vaccination studies of aspergillosis in turkeys: subcutaneous inoculation with several vaccine preparations followed by aerosol challenge exposure. Am J Vet Res, 1982, 43(3), 488-492.

[30] de Repentigny, L.; Petitbois, S.; Boushira, M.; Michaliszyn, E.; Senechal, S.; Gendron, N.; Montplaisir, S. Acquired immunity in experimental murine aspergillosis is mediated by macrophages. Infect Immun, 1993, 61(9), 37913802.

[31] Cenci, E.; Mencacci, A.; Bacci, A.; Bistoni, F.; Kurup, V. P.; Romani, L. T cell vaccination in mice with invasive pulmonary aspergillosis. $\mathrm{J}$ Immunol, 2000, 165(1), 381-388.

[32] Ito, J. I.; Lyons, J. M. Vaccination of corticosteroid immunosuppressed mice against invasive pulmonary aspergillosis. J Infect Dis, 2002, 186(6), 869-871. 
[33] Denikus, N.; Orfaniotou, F.; Wulf, G.; Lehmann, P. F.; Monod, M.; Reichard, U. Fungal antigens expressed during invasive aspergillosis. Infect Immun, 2005, 73(8), 4704-4713.

[34] Bozza, S.; Gaziano, R.; Lipford, G. B.; Montagnoli, C.; Bacci, A.; Di Francesco, P.; Kurup, V. P.; Wagner, H.; Romani, L. Vaccination of mice against invasive aspergillosis with recombinant Aspergillus proteins and CpG oligodeoxynucleotides as adjuvants. Microbes Infect, 2002, 4(13), 1281-1290.

[35] Ito, J. I.; Lyons, J. M.; Hong, T. B.; Tamae, D.; Liu, Y. K.; Wilczynski, S. P.; Kalkum, M. Vaccinations with recombinant variants of Aspergillus fumigatus allergen Asp f 3 protect mice against invasive aspergillosis. Infect Immun, 2006, 74(9), 5075-5084.

[36] Asif, A. R.; Oellerich, M.; Amstrong, V. W.; Gross, U.; Reichard, U. Analysis of the cellular Aspergillus fumigatus proteome that reacts with sera from rabbits developing an acquired immunity after experimental aspergillosis. Electrophoresis, 2010, 31(12), 1947-1958.

[37] Asif, A. R.; Oellerich, M.; Amstrong, V. W.; Riemenschneider, B.; Monod, M.; Reichard, U. Proteome of conidial surface associated proteins of Aspergillus fumigatus reflecting potential vaccine candidates and allergens. J Proteome Res, 2006, 5(4), 954-962.

[38] Nierman, W. C.; Pain, A.; Anderson, M. J.; Wortman, J. R.; Kim, H. S.; Arroyo, J.; Berriman, M.; Abe, K.; Archer, D. B.; Bermejo, C.; Bennett, J.; Bowyer, P.; Chen, D.; Collins, M.; Coulsen, R.; Davies, R.; Dyer, P. S.; Farman, M.; Fedorova, N.; Feldblyum, T. V.; Fischer, R.; Fosker, N.; Fraser, A.; Garcia, J. L.; Garcia, M. J.; Goble, A.; Goldman, G. H.; Gomi, K.; Griffith-Jones, S.; Gwilliam, R.; Haas, B.; Haas, H.; Harris, D.; Horiuchi, H.; Huang, J.; Humphray, S.; Jimenez, J.; Keller, N.; Khouri, H.; Kitamoto, K.; Kobayashi, T.; Konzack, S.; 
Kulkarni, R.; Kumagai, T.; Lafon, A.; Latge, J. P.; Li, W.; Lord, A.; Lu, C.; Majoros, W. H.; May, G. S.; Miller, B. L.; Mohamoud, Y.; Molina, M.; Monod, M.; Mouyna, I.; Mulligan, S.; Murphy, L.; O'Neil, S.; Paulsen, I.; Penalva, M. A.; Pertea, M.; Price, C.; Pritchard, B. L.; Quail, M. A.; Rabbinowitsch, E.; Rawlins, N.; Rajandream, M. A.; Reichard, U.; Renauld, H.; Robson, G. D.; Rodriguez de Cordoba, S.; Rodriguez-Pena, J. M.; Ronning, C. M.; Rutter, S.; Salzberg, S. L.; Sanchez, M.; Sanchez-Ferrero, J. C.; Saunders, D.; Seeger, K.; Squares, R.; Squares, S.; Takeuchi, M.; Tekaia, F.; Turner, G.; Vazquez de Aldana, C. R.; Weidman, J.; White, O.; Woodward, J.; Yu, J. H.; Fraser, C.; Galagan, J. E.; Asai, K.; Machida, M.; Hall, N.; Barrell, B.; Denning, D. W. Genomic sequence of the pathogenic and allergenic filamentous fungus Aspergillus fumigatus. Nature, 2005, 438(7071), 1151-1156.

[39] Suh, M. J.; Fedorova, N. D.; Cagas, S. E.; Hastings, S.; Fleischmann, R. D.; Peterson, S. N.; Perlin, D. S.; Nierman, W. C.; Pieper, R.; Momany, M. Development stage-specific proteomic profiling uncovers small, lineage specific proteins most abundant in the Aspergillus fumigatus conidial proteome. Proteome Sci, 2012, 10(1), 30.

[40] Banerjee, B.; Kurup, V. P.; Greenberger, P. A.; Johnson, B. D.; Fink, J. N. Cloning and expression of Aspergillus fumigatus allergen Asp f 16 mediating both humoral and cell-mediated immunity in allergic bronchopulmonary aspergillosis (ABPA). Clin Exp Allergy, 2001, 31(5), 761-770.

[41] Crameri, R. Recombinant Aspergillus fumigatus allergens: from the nucleotide sequences to clinical applications. Int Arch Allergy Immunol, 1998, 115(2), 99114. 
[42] Reichard, U.; Cole, G. T.; Ruchel, R.; Monod, M. Molecular cloning and targeted deletion of PEP2 which encodes a novel aspartic proteinase from Aspergillus fumigatus. Int J Med Microbiol, 2000, 290(1), 85-96.

[43] Arroyo, J.; Sarfati, J.; Baixench, M. T.; Ragni, E.; Guillen, M.; Rodriguez-Pena, J. M.; Popolo, L.; Latge, J. P. The GPI-anchored Gas and Crh families are fungal antigens. Yeast, 2007, 24(4), 289-296.

[44] Diaz-Arevalo, D.; Bagramyan, K.; Hong, T. B.; Ito, J. I.; Kalkum, M. CD4+ T cells mediate the protective effect of the recombinant Asp f3-based anti-aspergillosis vaccine. Infect Immun, 2011, 79(6), 2257-2266.

[45] Diaz-Arevalo, D.; Ito, J. I.; Kalkum, M. Protective Effector Cells of the Recombinant Asp f3 Anti-Aspergillosis Vaccine. Front Microbiol, 2012, 3, 299.

[46] De Luca, A.; lannitti, R. G.; Bozza, S.; Beau, R.; Casagrande, A.; D'Angelo, C.; Moretti, S.; Cunha, C.; Giovannini, G.; Massi-Benedetti, C.; Carvalho, A.; Boon, L.; Latge, J. P.; Romani, L. CD4(+) T cell vaccination overcomes defective cross-presentation of fungal antigens in a mouse model of chronic granulomatous disease. J Clin Invest, 2012, 122(5), 1816-1831.

[47] Wuthrich, M.; Hung, C. Y.; Gern, B. H.; Pick-Jacobs, J. C.; Galles, K. J.; Filutowicz, H. I.; Cole, G. T.; Klein, B. S. A TCR transgenic mouse reactive with multiple systemic dimorphic fungi. J Immunol, 2011, 187(3), 1421-1431.

[48] Wuthrich, M.; Filutowicz, H. I.; Warner, T.; Deepe, G. S., Jr.; Klein, B. S. Vaccine immunity to pathogenic fungi overcomes the requirement for CD4 help in exogenous antigen presentation to $\mathrm{CD} 8+\mathrm{T}$ cells: implications for vaccine development in immune-deficient hosts. J Exp Med, 2003, 197(11), 1405-1416.

[49] Huffnagle, G. B.; Yates, J. L.; Lipscomb, M. F. Immunity to a pulmonary Cryptococcus neoformans infection requires both CD4+ and CD8+ T cells. $\mathrm{J}$ Exp Med, 1991, 173(4), 793-800. 
[50] Fierer, J.; Waters, C.; Walls, L. Both CD4+ and CD8+ T cells can mediate vaccine-induced protection against Coccidioides immitis infection in mice. $J$ Infect Dis, 2006, 193(9), 1323-1331.

[51] Carvalho, A.; De Luca, A.; Bozza, S.; Cunha, C.; D'Angelo, C.; Moretti, S.; Perruccio, K.; Iannitti, R. G.; Fallarino, F.; Pierini, A.; Latge, J. P.; Velardi, A.; Aversa, F.; Romani, L. TLR3 essentially promotes protective class I-restricted memory CD8(+) T-cell responses to Aspergillus fumigatus in hematopoietic transplanted patients. Blood, 2012, 119(4), 967-977.

[52] Leal, S. M., Jr.; Vareechon, C.; Cowden, S.; Cobb, B. A.; Latge, J. P.; Momany, M.; Pearlman, E. Fungal antioxidant pathways promote survival against neutrophils during infection. J Clin Invest, 2012, 122(7), 2482-2498.

[53] Levitz, S. M.; North, E. A. Lymphoproliferation and cytokine profiles in human peripheral blood mononuclear cells stimulated by Cryptococcus neoformans. $\mathrm{J}$ Med Vet Mycol, 1997, 35(4), 229-236.

[54] Levitz, S. M.; Diamond, R. D. Killing of Aspergillus fumigatus spores and Candida albicans yeast phase by the iron-hydrogen peroxide-iodide cytotoxic system: comparison with the myeloperoxidase-hydrogen peroxide-halide system. Infect Immun, 1984, 43(3), 1100-1102.

[55] Diamond, R. D.; Clark, R. A. Damage to Aspergillus fumigatus and Rhizopus oryzae hyphae by oxidative and nonoxidative microbicidal products of human neutrophils in vitro. Infect Immun, 1982, 38(2), 487-495. 